\title{
PELATIHAN PERANCANGAN DRIP IRIGATION SEBAGAI TEKNIK PENYIRAMAN EFEKTIF PADA LAHAN KERING
}

\section{DRIP IRRIGATION DESIGN TRAINING AS EFFECTIVE WATERING TECHNIQUES IN DRY LAND}

\author{
Nanda Novita ${ }^{1)}$, Fakhrah $^{2)}$, Ratna Unaida ${ }^{3)}$, Riska Imanda ${ }^{4)}$ \\ ${ }^{1}$ Pendidikan Fisika, Fakultas Keguruan dan Ilmu Pendidikan, Universitas Malikussaleh \\ ${ }^{2,3,4}$ Pendidikan Kimia, Fakultas Keguruan dan Ilmu Pendidikan, Universitas \\ Malikussaleh \\ 2Email: fakhrah@unimal.ac.id
}

Naskah diterima tanggal 05-10-2021, direvisi tanggal 30-11-2021, disetujui tanggal 01-12-2021

\begin{abstract}
Abstrak: Pelatihan perancangan drip irrigation dilakukan sebagai teknik penyiraman yang efektif dan efisien serta solusi mengatasi kekurangan air pada lahan kering di Desa Paloh Gadeng. Sebelum pelaksanaan kegiatan pengabdian terlebih dahulu dilakukan survei lahan dan perizinan serta menentukan kelompok tani yang terpilih sebagai sasaran kegiatan pengabdian. Pelaksanaan kegiatan ini dilakukan melalui tiga tahap. Tahap pertama adalah sosialisasi dan diskusi. Tahap kedua adalah persiapan alat dan bahan serta pelatihan perancangan alat drip irigation. Tahap ketiga adalah penggunaan dan pemasangan alat drip irigation pada lahan yang telah dipersiapkan. Pada akhir kegiatan dilakukan evaluasi untuk melihat respon peserta terhadap pelaksanaan kegiatan. Secara umum pelaksanaan kegiatan pengabdian kepada masyarakat yang sudah dilakukan mendapat respon positif dari peserta yang terlibat dimana dalam kegiatan ini adalah petani. Nilai respon rata-rata dari peserta sebesar $56 \%$ sangat setuju dan $44 \%$ setuju. Hasil ini menunjukkan bahwa pelaksanaan kegiatan sangat bermanfaat, sesuai dengan kebutuhan, meningkatkan ketrampilan, memberikan solusi terhadap permasahan yang dihadapi mitra.
\end{abstract}

Kata Kunci: Drip irigation, Teknik penyiraman, Lahan kering

Abstract: The drip irrigation design training was carried out as an effective and efficient watering technique as well as a solution to overcome water shortages on dry land in Paloh Gadeng Village. Prior to the implementation of service activities, land surveys and permits are carried out and determine the selected farmer groups as targets for service activities. The implementation of this activity is carried out in three stages. The first stage is socialization and discussion. The second stage is the preparation of tools and materials and training in the design of drip irrigation equipment. The third stage is the use and installation of drip irrigation equipment on the prepared land. At the end of the activity, an evaluation was carried out to see the participant's response to the implementation of the activity. In general, the implementation of community service activities that have been carried out has received a positive response from the participants involved where in this activity are farmers. The average response value of 
INTEGRITAS : Jurnal Pengabdian

Vol 5 No 2 Desember 2021

ISSN 2580 - 7978 (cetak) ISSN 2615 - 0794 (online)

participants was $56 \%$ strongly agree and $44 \%$ agree. These results indicate that the implementation of activities is very useful, according to needs, improving skills, providing solutions to problems faced by partners.

Keywords: Drip irigation, Watering technique, Dry land

\section{PENDAHULUAN}

Desa Paloh Gadeng adalah salah satu Desa yang terletak di Kecamatan Dewantara Kabupaten Aceh Utara, dengan jumlah penduduk sekitar 1.800 jiwa. Desa ini dikelilingi oleh sungai dan perbukitan, seiring dengan bertambahnya jumlah penduduk daerah perbukitan sebagian sudah diratakan dan digunakan sebagai tempat tinggal dan lahan pertanian. Mayoritas penduduk Desa memanfaakan lahan di sekitar tempat tinggal untuk memenuhi kebutuhan seharihari, lahan yang berada di dekat sungai dimanfaatkan sebagai sebagai tambak sedangkan daerah perbukitan dimanfaatkan oleh masyarakat sekitar untuk bercocok tanam. Penduduk Desa yang bekerja sebagai petani biasanya menanam tanaman seperti jagung, singkong, pisang, kacang, cabai, semangka dan lain-lain. Meskipun begitu masyarakat Desa Paloh Gadeng masih banyak menghadapi masalah dan kekurangan dalam pengolahan lahan.

Secara umum lahan di Desa Paloh Gadeng adalah lahan kering, cenderung berpasir dan berkerikil (Gambar 1). Untuk memenuhi kebutuhan pangan penduduk yang semakin bertambah secara signifikan serta mendukung pemantapan ketahanan pangan pengelolaan lahan kering sangat perlu dilakukan (Krisyuniawan \& Gunawan, 2020). Selain itu sulitnya mendapatkan sumber air untuk menyiram tanaman juga menjadi masalah, sehingga mengganggu pertumbuhan tanaman yang akhirnya berdampak pada hasil panen menjadi kurang maksimal. Air bagi tanaman merupakan sumber daya vital yang sangat penting karena proses fisiologis dan pertumbuhan tanaman tidak optimal jika kekurangan air (Mustofa A et al., 2020). 


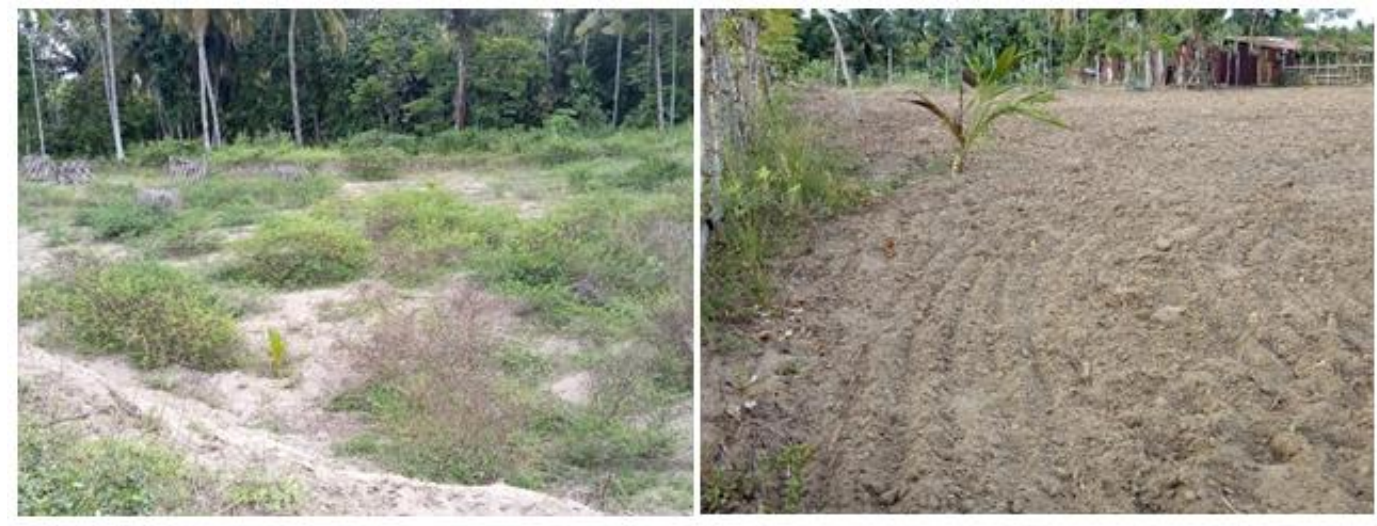

Gambar 1. Kondisi lahan di Desa Paloh Gadeng

Ketersediaan air saat musim kemarau merupakan permasalahan utama yang dihadapi oleh petani di Desa Paloh Gadeng. Saat musim kemarau sering terjadi gagal panen karena tidak cukupnya air yang didapatkan tanaman, hal itu disebabkan karena persediaan air tanah di Desa Paloh Gadeng kurang baik. Untuk mengatasi kekurangan air, para petani membuat tempat penampungan air pada tanah yang di gali berbentuk pesegi dengan luas 2,5 x 2,5 meter dan memiliki kedalaman 2 meter, kemudian dilapisi dengan terpal agar air yang ditampung tidak diserap kembali oleh tanah (Gambar 2). Saat musim hujan bak penampungan berfungsi untuk menampung air hujan. Sedangkan saat musim kemarau penampungan di isi dengan air yang bersumber dari sumur. Teknik penyiraman yang dilakukan petani masih konvensional, yaitu menyiram tanaman tanpa memperhatikan dan memperhitungkan kondisi air dalam tanah. Penggunaan air yang tidak efektif dan efisien ini menyebabkan meningkatnya jumlah air yang dibutuhkan. Selain itu air yang diberikan ke tanaman tidak tepat sasaran sehingga banyak air yang terbuang sia-sia dan mencukupi, sehingga pertumbuhan tanaman tidak optimal. Oleh karena itu petani perlu diperkenalkan metode penyiraman yang efektif seperti drip irigation (irigasi tetes) yang penggunaan airnya lebih efisien dengan sistem kontrol yang dapat mengendalikan pemberian air secara efektif. 


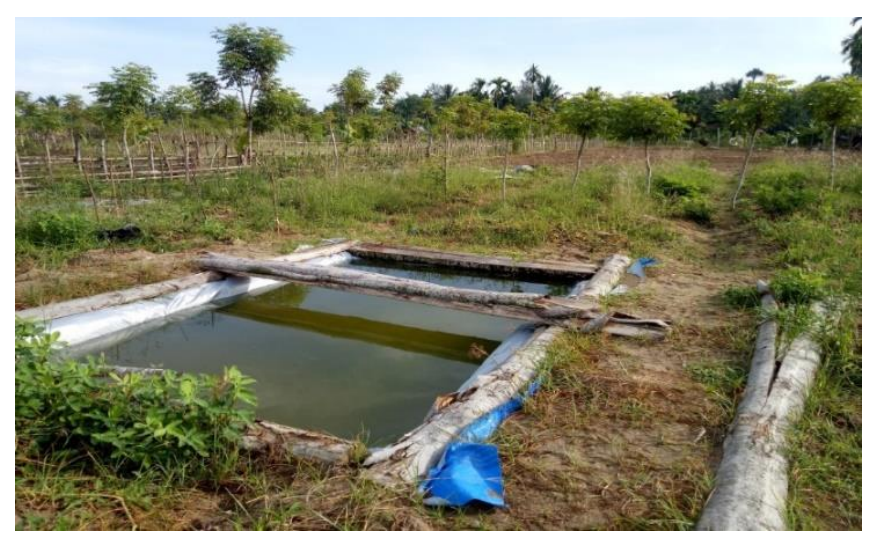

Gambar 2. Penampungan air

Drip irrigation merupakan alat yang bekerja memberikan air secara optimal pada tanaman dengan cara meneteskan air pada lubang-lubang yang ada, sehingga dapat mengoptimalkan pemberian air pada tanaman meskipun ketersediaan air tanah yang terbatas di daerah tersebut (Ekaputra et al., 2017). Drip irrigation merupakan teknik pemberian air secara langsung pada tanaman, baik pada area akar dan permukaan tanah melalui tetesan perlahan dan kontinu (Ridwan D, 2013). Penggunaan air dengan sistem irigasi tetes dalam pertanian sangan efektif dan efisien dengan efisiensinya mencapai 80-95\% (Udiana I M et al., 2014). Penyiraman tanaman menggunakan irigasi tetes dilakukan dengan memanfaatkan alat aplikasi (applicator, emission device) yang dapat mengalirkan air dengan frekuensi inggi dan debit yang rendah di sekitar akar tanaman (Sapei A, 2006).

Keunggulan Drip irrigation dibandingkan dengan metode irigasi lainnya, yaitu meningkatkan nilai guna air, meningkatkan efisiensi dan efektifitas penyiraman, menekan pertumbuhan gulma, meningkatkan pertumbuhan tanaman dan hasil, serta menghemat tenaga (Widiastuti \& Susilo Wijayanto, 2018). Berdasarkan uraian diatas, akan dilakukan pengabdian kepada masyarakat terkait perancangan drip irrigation kepada para petani di Desa Paloh Gadeng. Tujuan kegiatan PKM ini adalah dapat mengetahui cara instalasi drip irrigation dengan baik, mengetahui spesifikasi pipa yang cocok dengan keadaan lahan, mengetahui cara menentukan debit air idel berdasarkan keadaan lahan, dan kebutuhan air tanaman agar umur pakai irigasi tetes menjadi panjang. 


\section{METODE}

Kegiatan pengabdian perancangan drip irigation di Desa Paloh Gadeng dilaksanakan melalui beberapa tahapan berikut:

1. Sosialisasi dan Diskusi

Tahap pertama pelaksanaan kegiatan program PKM adalah sosialisasi yang dilakukan dengan memberikan pemaparan materi terkait teknik penyiraman tanaman yang efektif menggunakan drip irigation dan bagaimana cara merancang drip irigation. Materi yang diberikan diharapkan dapat meberikan pengetahuan dan pemahaman tentang bagaimana cara memanfaatkan air dilahan kering agar penyiraman tanaman lebih efektif dan efisien. Setelah pemaparan materi kemudian dilanjutkan dengan diskusi tanya jawab antara pemateri dengan mitra.

2. Perancangan alat drip irrigation

Pada tahapan ini petani dijelaskan alat dan bahan yang dibutuhkan dan cara merancang serta uji coba dan cara kerja alat drip irigation.

3. Penggunaan Alat

Setelah alat dirancang tahap berikutnya adalah penggunaan alat drip irigation pada lahan pertanian mitra. Alat yang telah dirancang ini diharapkan dapat berfungsi secara maksimal.

\section{HASIL DAN PEMBAHASAN}

Sebelum melaksanakan kegiatan pengabdian tim PKM terlebih dahulu melakukan observasi lahan yang berada di Desa Paloh Gadeng, wawancara, dan diskusi mengenai permasalahan yang dihadapi petani. Dari hasil observasi diperoleh informasi terkait permasalahan yang dihadapi petani. Salah satu permasalahan yang paling penting untuk dicarikan solusi adalah bagaimana cara mengelola lahan kering yang kekurangan air untuk meningkatkan hasil pertanian. Setelah survei lokasi dan perizinan dilakukan, tim pengabdian menentukan kelompok tani yang terpilih sebagai peserta kegiatan pengabdian. melakukan kesapakatan bersama tentang kontribusi dari kelompok tani yan terpilih selama pelaksanaan kegiatan, penentuan lokasi/lahan untuk implementasi sistem drip irrigation, perancangan dan penggunaan alat drip irrigation serta garis besar 


\section{INTEGRITAS : Jurnal Pengabdian}

Vol 5 No 2 Desember 2021

ISSN 2580 - 7978 (cetak) ISSN 2615 - 0794 (online)

kegaiatan-kegiatan yang akan dilaksanakan. Untuk tahapan awal kelompok tani yang terpilih diminta untu mempersiapkan lahan siap tanam.
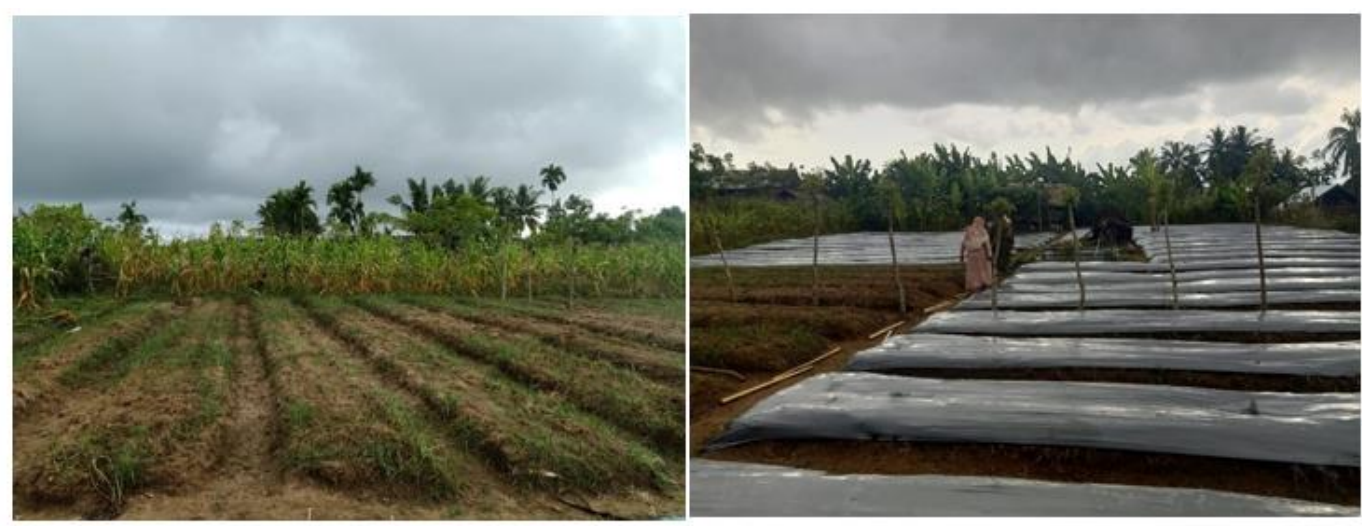

Gambar 3. Persiapan lahan siap tanam

Tahap pertama pelaksanaan kegiatan pengabdian adalah sosialisasi kegiatan. Pada tahap ini tim pelaksana memberikan materi meliputi teknik penyiraman sederhana yang efektif yaitu menggunakan drip irrigation, memamparkan kelebihan serta kekurangannya, alat dan bahan yang digunakn untuk merancang drip irrigation, serta bagaimana cara merancang alat. Selama kegiatan sosialisasi para peserta sangat antusias dan aktif dalam bertanya terkait materi yang sudah dipaparkan. Besar harapan mereka dengan menggunakan drip irigation untuk menyiram tanaman akan meringankan dan memudahkan petani. Selama ini petani menyiram tanaman masih menggunakan cara konvensonal yang sangat menguras tenaga, membutuhkan waktu yang lama, pemborosan penggunaan air, dan penyerapan air tidak maksimal oleh tanaman.

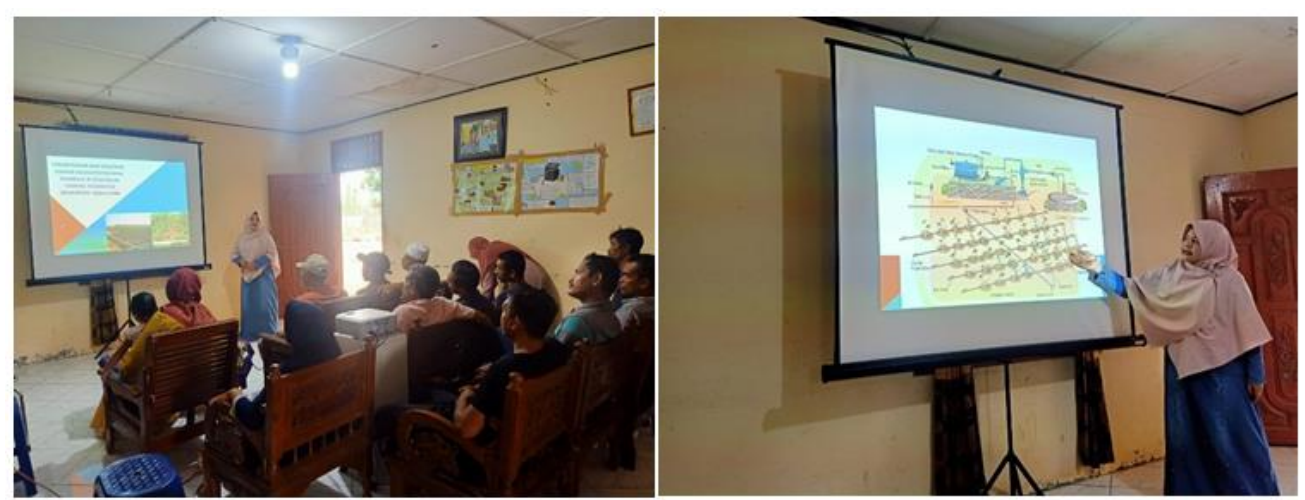

Gambar 4. Pemaparan materi drip irigation 
Tahapan kedua adalah perancangan alat drip irrigation, sebelum meracang terlebih dahulu dijelaskan alat dan bahan yan digunakan serta fungsi dari masingmasig alat dan bahan. Desain model drip irigation dirancang didasarkan pada kemudahan penggunaan, mudah mendapatkan material, pembuatan dan penerapannya, memiliki kinerja yang baik, dengan biaya investasi yang murah.

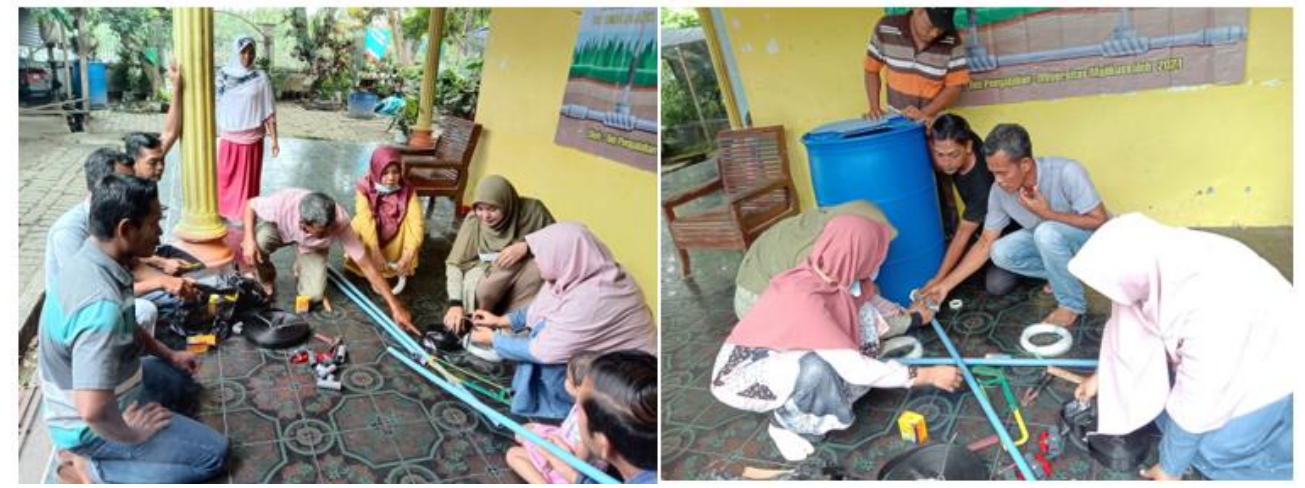

Gambar 5. Persiapan alat dan bahan drip irrigation

Prinsip kerja yang paling dasar dari drip irrigation adalah sistem pengaliran air yang diangkat menggunakan pompa dari sumbernya yaitu sumur ke tangki penampung. Air disaring terlebih dahulu melalui saringan inlet sebelum masuk ke tangki, Air dari tangka disaring kembali melalui saringan outlet, kemudian di salurkan melalui jaringan utama (pipa utama), lalu didistribusikan melalui jaringan pembagi (lateral) dan langsung di teteskan ke daerah perakaran tanaman melalui emitter. Saringan berfungsi untuk menyaring semua kotoran yang masuk pada tangki dan jaringan sehingga terhindar dari sumbatan. Pipa utama PVC (Gambar 6.e) berfungsi sebagai pipa pendistribusi air dari tangki ke pipa sub utama. Pipa sub utama (Gambar 6.f) berfungsi sebagai pipa pendistribusi dari pipa utama ke selang drip. Selang drip hidrosol (Gambar 6.g) digunakan pada drip line. Sistem pemasangan, selang drip hidrosol ini tersambung langsung pada pipa sub utama yang dibagian ujungnya sudah dipasang keran. Selanjutnya selang piping (Gambar 6.h) dibuat lancip guna memudahkan pemasangan pada selang drip hydrosol serta menghindari sumbatan. Sistem pengaturan tetesan diatur dengan cara mengatur putaran keran dengan debit tetesan yang diperlukan. 


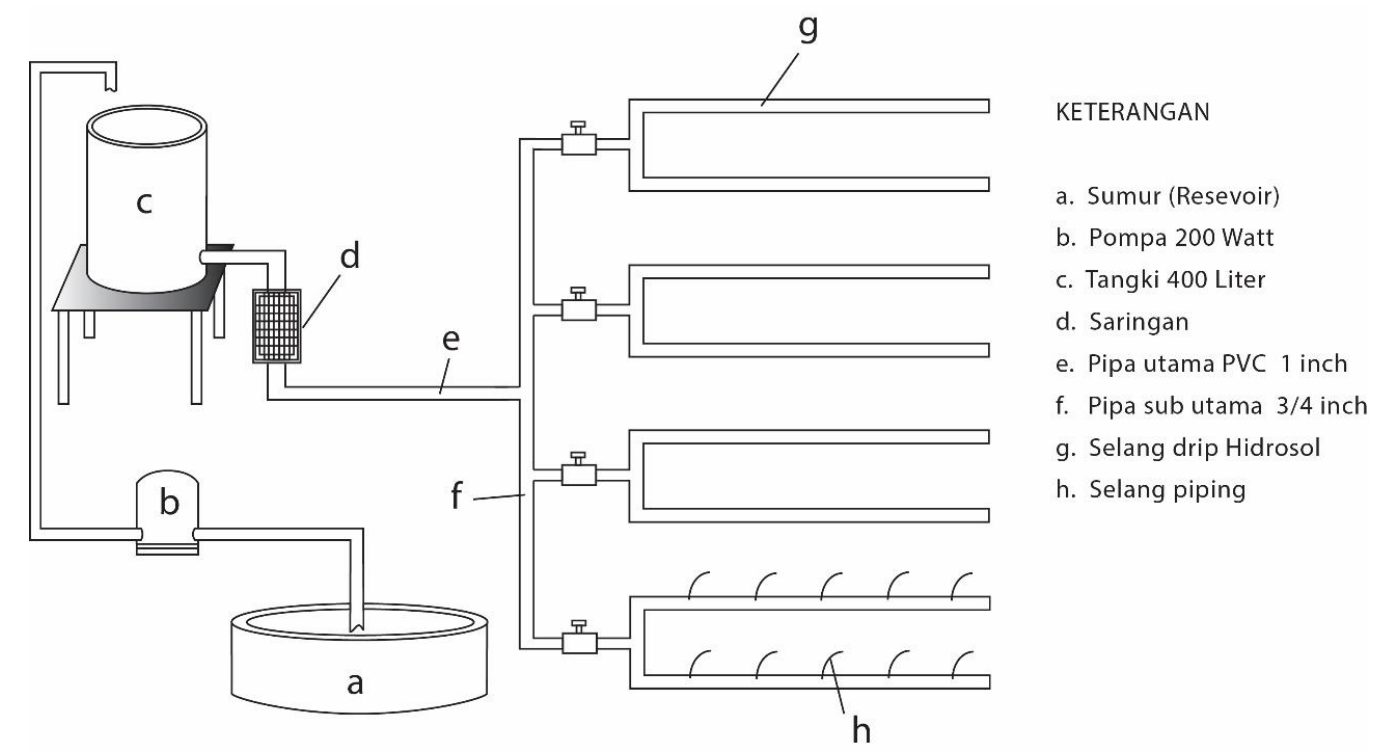

Gambar 6. Desain alat drip irrigation

Tahapan selanjutnya adalah instalasi drip irigation sebagai alat penyiraman tanaman yang langsung diaplikasikan pada lahan. Adapun tahapannya adalah instalasi penampungan air seperti terlihat pada gambar 7 .

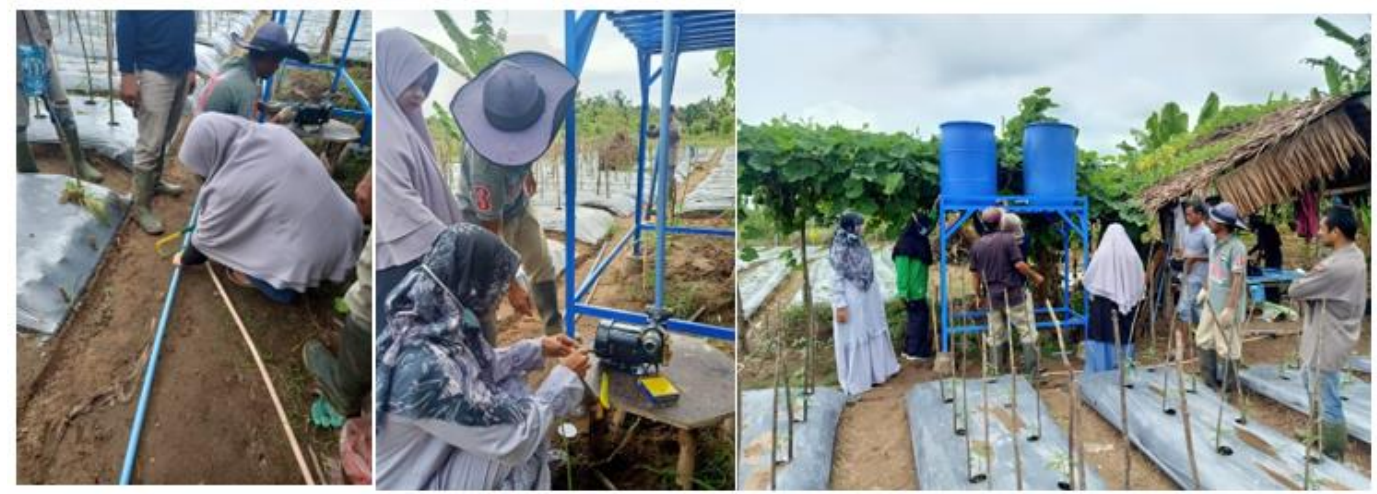

Gambar 7. Proses instalasi tangki penampungan air 
Tahapan berikutnya adalah membuat drip line untuk penyiraman langsung pada tanaman.

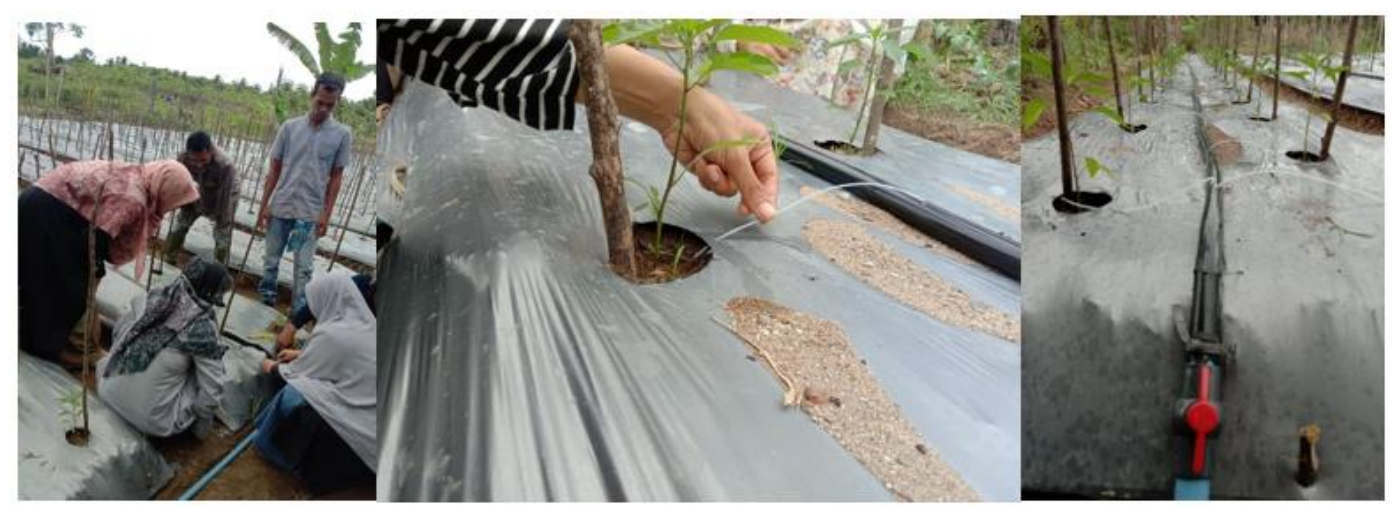

Gambar 8. Proses instalasi drip irigation
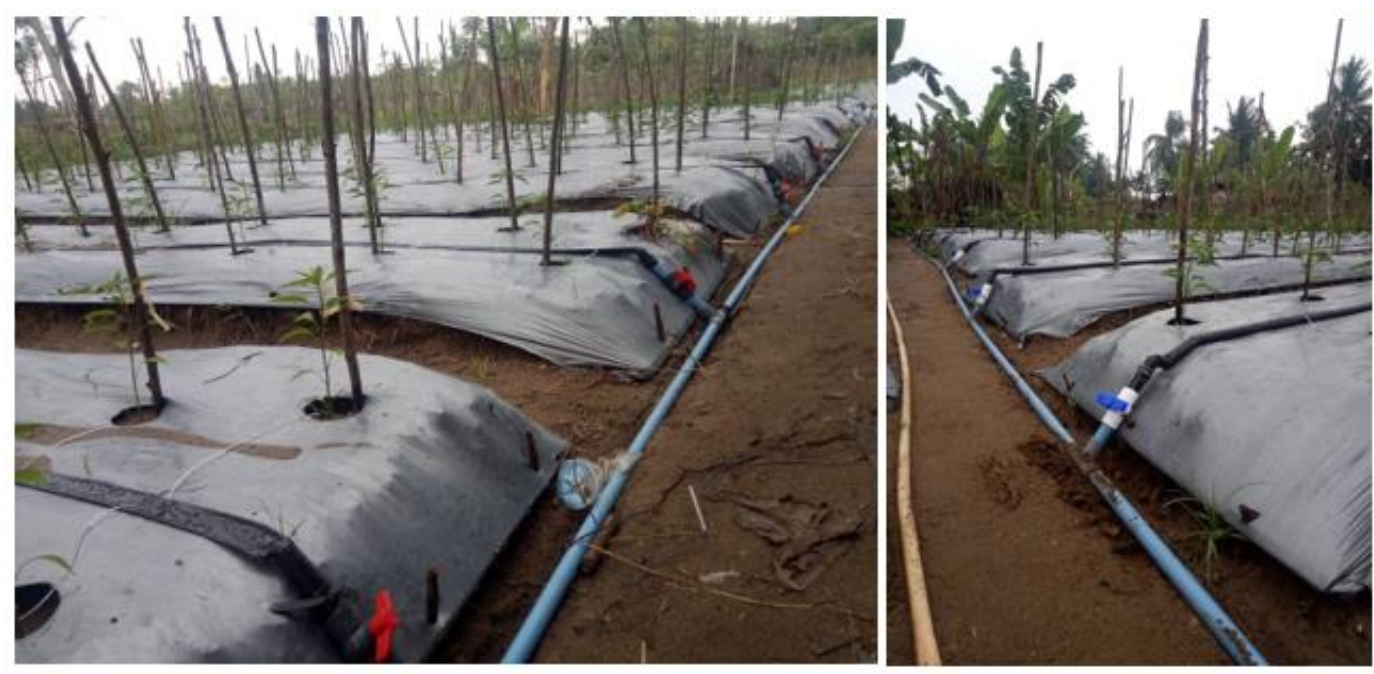

Gambar 9. Bedengan yang sudah mengguakan drip irigation

Setelah proses instalasi drip irrigation pada lahan tanaman cabai, pendampingan petani dalam pemeliharaan drip irigation terus dilakukan. Setelah menggunakan drip irigation petani merasa sangat terbantu dalam menyiram tanaman. Hal penting yang perlu diperhatikan dan diatur adalah debit tetes air yang mengenai tanaman dan durasi waktu pemyiraman harus benar-benar disesuikan dengan kebutuhan air tanaman. Secara garis besar, kegiatan pengabdian berjalan dengan lancar. Dengan adanya sistem drip irigation, petani di Desa Paloh Gadeng dapat bertani secara efektif tidak hanya pada saat musim penghujan saja tapi dapat terus dilakukan sepanjang tahun. 
INTEGRITAS : Jurnal Pengabdian

Vol 5 No 2 Desember 2021

ISSN 2580 - 7978 (cetak) ISSN 2615 - 0794 (online)

Pada akhir kegiatan dilakukan evaluasi akhir, yang dilakukan setelah pemasangan alat drip irrigation pada lahan tanaman cabai milik petani, dengan cara membagikan angket respon kepada seluruh petani yang telah mengikuti kegiatan pengabdian secara keseluruhan dari awal sampai akhir. Pembagian angket respon ini untuk melihat bagaimana respon petani terhadap pelaksanaan kegiatan pengabdian yang sudah dilakukan. Pernyataan angket respon yang digunakan ditunjukkan pada Tabel 1 berikut.

Tabel 1. Angket Respon

\begin{tabular}{|c|c|c|c|c|}
\hline NO & PERNYATAAN & SS & TS & STS \\
\hline 1 & $\begin{array}{l}\text { Pelatihan yang diberikan sesuai dengan kebutuhan } \\
\text { mitra }\end{array}$ & & & \\
\hline 2 & $\begin{array}{l}\text { Saya merasa puas dengan kegiatan "Pelatihan } \\
\text { Perancangan Drip Irigation Sebagai Teknik } \\
\text { Penyiraman Efektif Pada Lahan Kering" yang } \\
\text { diselenggarakan oleh tim PKM UNIMAL }\end{array}$ & & & \\
\hline 3 & $\begin{array}{l}\text { Cara penyampaian materi pelatihan menarik dan } \\
\text { mudah dipahami }\end{array}$ & & & \\
\hline 4 & $\begin{array}{l}\text { Mitra bersedia mengikuti PKM sesuai jadwal dan } \\
\text { rincian kegiatan yang sudah di rancang }\end{array}$ & & & \\
\hline 5 & $\begin{array}{l}\text { Kegiatan PKM yang diselenggarakan sesuai dengan } \\
\text { harapan saya }\end{array}$ & & & \\
\hline 6 & $\begin{array}{l}\text { Semua anggota yang terlibat dalam kegiatan PKM } \\
\text { memberikan pelayanan maksimal sesuai dengan } \\
\text { kebutuhan saya }\end{array}$ & & & \\
\hline 7 & $\begin{array}{l}\text { Setiap keluhan/pertanyaan/permasalahan yang ajukan } \\
\text { peserta ditindaklanjuti dengan baik oleh anggota yang } \\
\text { terlibat }\end{array}$ & & & \\
\hline 8 & $\begin{array}{l}\text { Jika kegiatan PKM ini diselenggarakan kembali, saya } \\
\text { bersedia untuk berpartisipasi dalam kegiatan tersebut, }\end{array}$ & & & \\
\hline 9 & $\begin{array}{l}\text { Kegiatan PKM yang diselenggarakan oleh tim } \\
\text { pengabdian UNIMAL sangat bermanfaat bagi saya. }\end{array}$ & & & \\
\hline 10 & $\begin{array}{l}\text { Kegiatan PKM berhasil meningkatkan ketrampilan } \\
\text { mitra terutama tentang Teknik penyiraman tanaman } \\
\text { Drip Irigation. }\end{array}$ & & & \\
\hline
\end{tabular}


Adapun hasil angket respon petani terhadap pelaksanaan kegiatan ditunjukkan oleh grafik pada Gambar 10 berikut.

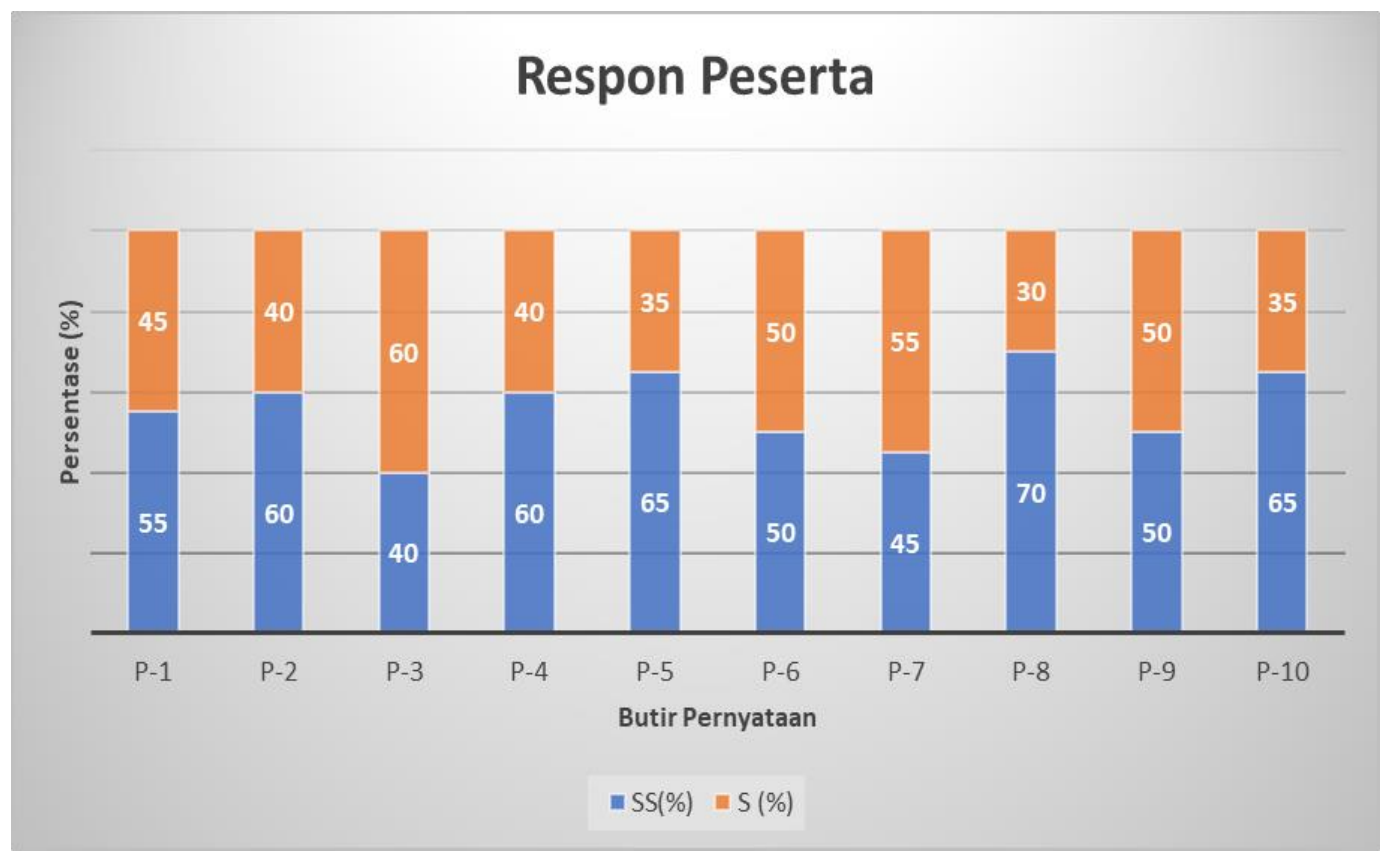

Gambar 10. Respon petani terhdap pelaksanaan kegiatan pelatihan.

Secara umum pelaksanaan kegiatan PKM yang sudah dilakukan mendapat respon positif dari peserta yang terlibat dimana dalam kegiatan ini adalah petani. Nilai respon rata-rata dari peserta sebesar 56\% sangat setuju dan $44 \%$ setuju. Hasil ini menunjukkan bahwa pelaksanaan kegiatan sangat bermanfaat, sesuai dengan kebutuhan, meningkatkan keterampilan, menjawab permasalahan yang dihadapi mitra, dan sesuai dengan harapan. Selain itu $70 \%$ peserta sangat setuju untuk ikut berpatisipasi jika kegiatan diselenggarakan kembali.

\section{KESIMPULAN}

Kegiatan Pengabdian Kepada Masyarakat (PKM) perancangan drip irrigation dilaksanakan di Desa Paloh Gadeng, Kecamatan Dewantara, Kabupaten Aceh Utara. Perancangan drip irrigation merupakan salah satu solusi yang dilakukan untuk menyelesaikan permasalahan masyarakat terutama di kalangan petani. Melalui sistem drip irrigation ini petani mendapat pengetahuan baru tentang teknik penyiraman yang efektif dan efisien, mengetahui spesifikasi drip irrigation yang sesuai dengan kondisi lahan pertanian, mengetahui cara instalasi drip irrigation yang baik, dan cara pemeliharaan alat. Dengan adanya sistem 
INTEGRITAS : Jurnal Pengabdian

Vol 5 No 2 Desember 2021

ISSN 2580 - 7978 (cetak) ISSN 2615 - 0794 (online)

irigasi tetes ini, masyarakat dapat terus melakukan aktivitas bertani sepanjang tahun.

\section{UCAPAN TERIMA KASIH}

Terima kasih disampaikan kepada LPPM Universitas Malikussaleh yang telah mendanai kegiatan pengabdian kepada masyarakat ini melalui dana PNBP tahun anggaran 2021 dan kelompok tani Desa Paloh Gadeng Kecamatan Dewantara Kabupaten Aceh Utara sebagai mitra dalam kegiatan ini.

\section{DAFTAR PUSTAKA}

Mustofa A, Yulius E, \& Paryati N. (2020). Uji Kinerja Emitter pada Sistem Irigasi Tetes. 8, 105-112.

Ekaputra, E. G., Yanti, D., Saputra, D., \& Irsyad, F. (2017). Rancang Bangun Sistem Irigasi Tetes untuk Budidaya Cabai (Capsicum Annum L.) dalam Greenhouse di Nagari Biaro, Kecamatan Ampek Angkek, Kabupaten Agam, Sumatera Barat. Jurnal Irigasi, 11(2).

Krisyuniawan, M. D., \& Gunawan, T. A. (2020). Pelatihan Pembuatan Irigasi Tetes Sederhana Guna Meningkatkan Hasil Lahan Talas Di Kampung Kiringan Baru. Abdipraja (Jurnal Pengabdian Kepada Masyarakat), 1(1).

Ridwan D. (2013). Model Jaringan Irigasi Tetes Berbasis Bahan Lokal Untuk Pertanian Lahan Sempit. 8, 90-98.

Sapei A. (2006). Irigasi Tetes (Drip/Trickle Irrigation). (A. Sapei, Ed.).

Udiana I M, Bunganaen W, \& Padja R A. Pa. (2014). Perencanaan Sistem Irigasi Tetes (Drip irrigation) Di Desa Besmarak Kabupaten Kupang. 3, 63-76.

Widiastuti, I., \& Susilo Wijayanto, D. (2018). Design of a Drip irrigation System for the Dragon Fruit Cultivation. Jurnal Keteknikan Pertanian, 6(1). 